\title{
基 \\ Efeito da dieta liquida no desempenho e custo de produção de bezerros leiteiros na fase de cria
}

\author{
[Effect of liquid diet on performance and production cost of dairy steers \\ in the pre-weaning phase]
}

\section{"Artigo Científico/Scientific Article"}

\author{
Antonio Leandro Chaves Gurgel ${ }^{1 *}$, Valdi Lima Junior ${ }^{2}$, Pedro Lucas Oliveira Câmara ${ }^{1}$, \\ Francisca Fernanda Silva Roberto ${ }^{3}$, Luana Andressa Costa Silva ${ }^{1}$, Leonia Régia Costa Silva ${ }^{2}$, \\ Emizael Menezes Almeida ${ }^{4}$, Juliana Caroline Santos Santana ${ }^{5}$
}

\author{
${ }^{1}$ Programa de Pós-Graduação em Produção Animal, Universidade Federal do Rio Grande do Norte, Macaíba-RN, Brasil. \\ ${ }^{2}$ Curso de Zootecnia, Universidade Federal do Rio Grande do Norte, Macaíba-RN, Brasil. \\ ${ }^{3}$ Programa de Pós-Graduação em Zootecnia, Universidade Federal da Paraíba, Areia-PB, Brasil. \\ ${ }^{4}$ Programa de Pós-Graduação em Ciência Animal, Universidade Federal de Mato Grosso do Sul, Campo Grande-MS, Brasil. \\ ${ }^{5}$ Curso de Zootecnia, Universidade Federal de Sergipe, Aracaju-SE, Brasil. \\ *Autor para correspondência/Corresponding author: E-mail: antonioleandro09@gmail.com
}

\begin{abstract}
Resumo
Objetivou-se avaliar o efeito da dieta líquida no desempenho de bezerros leiteiros e nos custos operacionais da fase de cria. O experimento foi conduzido, entre os meses de novembro e dezembro de 2015. Foram utilizados 10 animais, distribuídos em delineamento inteiramente casualizado com dois tratamentos (leite integral bovino ou sucedâneo) e cinco repetições. As variáveis de desempenho avaliadas foram: peso, ganho médio diário (GMD), ganho de peso total (GPT), e medidas biométricas (altura de cernelha, comprimento corporal, perímetro torácico, largura de garupa e de peito). Os indicadores econômicos analisados foram: os custos totais com a dieta líquida, com o concentrado e os custos com a mão de obra. Foi avaliado os encargos e impostos, despesas diversas, receita bruta, custo de oportunidade, lucro operacional e lucro total. Foi observado efeito da dieta liquida para peso final, GMD e GPT, os animais que receberam leite integral tiverem GMD 38\% superior. Não houve efeito de tratamento para as medidas biométricas. O item de maior participação nos custos de produção foi a dieta $75 \%$ e $70 \%$ para leite e sucedâneo, respectivamente, seguido pelo custo com mão de obra, o leite tornou o sistema mais oneroso. A receita bruta estimada foi maior para os animais que receberam leite integral (548,5 vs 353,5 US\$). O balanço econômico foi negativo para ambas as dietas. Bezerros leiteiros recebendo leite bovino na fase de cria na dieta líquida, apresentam um desempenho superior aos que recebem sucedâneo. Mesmo com desempenho superior, o leite integral tornou o sistema mais oneroso.
\end{abstract}

Palavras-chave: bovinocultura; leite; substituto lácteo; viabilidade econômica.

\begin{abstract}
This study proposes to examine the effect of a liquid diet on the performance of dairy steers and on the operational costs of the pre-weaning phase. The experiment took place between November and December 2015. Ten animals were assigned to one of two treatments (whole cow's milk or milk replacer) in a completely randomized design with five replicates. The following performance variables were evaluated: weight, average daily gain (ADG), total weight gain (TWG), and biometric measurements (withers height, body length, heart girth, rump width, and chest width). The following economic indicators were analyzed: total expenditure on liquid diet, total expenditure on concentrate and labor costs. Charges and taxes, general expenses, gross revenue, opportunity cost, operating cost, and total profit were also calculated. The liquid diet affected final weight, ADG, and TWG, and the animals that received whole milk had a 38\% higher ADG. Biometric measurements were not influenced by the treatments. The most representative item in production costs was the diet ( $75 \%$ and $70 \%$ for cow's milk and milk replacer, respectively), followed by labor costs. Cow's milk rendered the system more costly. The estimated gross revenue was higher for the animals which received whole
\end{abstract}


milk (US\$ 548.5 vs. US\$ 353.5). Both diets resulted in a negative economic balance. Dairy steers receiving cow's milk in a liquid diet during the pre-weaning phase have better performance than those fed milk replacer. Despite the superior performance, whole milk increased the cost of the system.

Keywords: cattle breeding; economic viability; milk; milk substitute.

\section{Introdução}

A criação de bezerros na maioria das explorações leiteiras no Brasil tem sido realizada de forma inadequada, uma vez que machos são, em sua maioria, descartados ao nascer, em razão do alto custo da dieta líquida, constituída de leite integral, durante a fase não-ruminante (Conceição et al., 2018; Reis et al., 2018).

Evidentemente há casos em que o produtor de leite não pode deixar definitivamente a criação de bezerros, pois traria prejuízo para seu sistema de produção. Nestes casos é preciso pensar no custo benefício e planejar mudanças para o futuro. Em países desenvolvidos praticamente $100 \%$ dos machos leiteiros são criados para a produção de carne, destacando-se a produção de vitelos (Resano et al., 2018). No Brasil, os machos de aptidão leiteira em sua grande maioria ainda não são criados para a produção de carne. Diante disso Salles e Lucci (2000) sugerem que a produção de carne por estes bezerros pode vir a contornar o seu alto custo de criação quando associadas às tecnologias. Dessa forma, é importante que se estude formas para melhorar o aproveitamento desses animais.

$\mathrm{Na}$ fase de cria o item que mais onera os custos de produção é a dieta líquida, composta na grande maioria por leite integral, chegando a representar de $70 \%$ a $80 \%$ dos custos de produção (Guerra et al., 2010; Santos e Lopes, 2014; Reis et al., 2018). Um bezerro chega a consumir até 240 litros de leite desde o nascimento até o desmame aos 60 dias de idade (Boito et al., 2015). Porém, o leite é o principal produto das propriedades leiteiras, sendo responsável por gerar quase que $100 \%$ da receita (Teixeira Júnior et al., 2017; Aguilar et al., 2018; Conceição et al., 2018).

Com isso a criação de bezerros/bezerras quando alimentados com leite integral compete de forma direta com a geração de receita da propriedade, o que torna imprescindível estudar sistemas de produção que venham diminuir os custos com essa fase, fundamental para o sucesso da atividade.

O sucedâneo é um produto largamente utilizado para evitar essa competição, na tentativa de diminuir os custos, porém existem algumas preocupações por parte dos produtores ao fazerem uso do sucedâneo, devido os animais não manterem o mesmo desempenho de animais que recebem apenas leite integral (Boito et al., 2015).

Isso se deve ao fato de existirem diversas marcas de sucedâneo no comércio e com diferentes composições. Quando o substituto lácteo não comporta os níveis nutricionais adequados e não é utilizado corretamente, pode acarretar alguns problemas nutricionais e digestivos tendo como destaque: excesso de amido e de fibra, tipo e inadequada incorporação da gordura e utilização de fontes proteicas de baixo aproveitamento ou que provocam transtornos digestivos nos bezerros, além de deterioração gradual na integridade das vilosidades intestinais, em consequência de reações alérgicas (Schäff et al., 2018).

Sendo assim, torna-se necessário avaliar a relação custo/benéfico ao se tomar a decisão de substituir em sua totalidade o leite integral pelo sucedâneo. Diante disso, objetivou-se avaliar o efeito da dieta líquida no desempenho de bezerros de aptidão leiteira e nos custos operacionais da fase de cria.

\section{Material e Métodos}

O experimento foi conduzido no setor de bovinocultura leiteira da Universidade Federal do Rio Grande do Norte (UFRN), Campus de Macaíba ( $5^{\circ} 53^{\prime \prime} 35.12^{\prime}$ sul e $35^{\circ} 21$ " 47.03' Oeste). O clima da região, de acordo com a classificação climática de Thornthwaite (1948), é subúmido seco, com excedente hídrico de maio a agosto. A precipitação média anual é de $1048 \mathrm{~mm} \mathrm{e}$ evapotranspiração potencial média acumulada anual de $1472 \mathrm{~mm}$. O período experimental teve duração de 60 dias, entre os meses de novembro e dezembro de 2015.

Foram utilizados 10 bezerros machos inteiros, recém-nascidos da raça Girolando, provenientes de propriedades leiteiras da região Agreste do Rio Grande do Norte e do setor de bovinocultura da UFRN. Os animais, ao chegarem ao setor de Bovinocultura de Leite, tanto aqueles oriundos das propriedades leiteiras como os provenientes do próprio setor, foram submetidos à 
inspeção clínica para registro das condições física e sanitária, identificados e pesados. Após passarem pelo protocolo de recepção, receberam um litro de colostro, com o auxílio de mamadeira para bezerro até o terceiro dia de vida, a partir de então ingressaram no experimento.

Os bezerros foram alojados em baias individuais, fixas, piso cimentado, cobertas com telha de barro, contendo bebedouros e comedouros de livre acesso tendo as mesmas condições ambientais (vento, irradiação solar e chuvas). Os animais apresentavam peso inicial de $26,5 \pm 3,6 \mathrm{~kg}$ e foram distribuídos aleatoriamente nos tratamentos: leite integral e sucedâneo. Foram fornecidos quatro litros da dieta divididos em dois turnos (manhã e tarde), com o auxílio de mamadeira para bezerro com capacidade de 2 litros. O leite integral foi fornecido imediatamente após a ordenha e não sofreu nenhum tipo de processamento.

O sucedâneo foi preparado diariamente, antes de cada refeição, misturando-se $10 \%$ do produto em água pré-aquecida e fornecido. Também foi ofertado ração peletizada própria para a categoria, adotando-se o consumo mínimo inicial de 50 gramas por animal e, após 24 horas do fornecimento, as sobras foram pesadas para o ajuste da quantidade fornecida, preconizando sobras de $15 \%$ (consumo ad libitum). Embora contribuam minimamente para o atendimento das exigências nutricionais, o fornecimento de alimentos sólidos nas primeiras semanas de vida tem importância significativa na colonização do rúmen por micro-organismos, no início da secreção salivar e no desenvolvimento ruminorreticular. A composição dos alimentos fornecidos aos animais está apresentada na tabela 1.

Tabela 1. Composição química da dieta fornecida durante a fase de cria.

\begin{tabular}{lccc} 
& Concentrado* & Sucedâneo* $^{*}$ & Leite** $^{* *}$ \\
\hline Matéria seca \% & 87,0 & 12,0 & - \\
Proteína Bruta \% & 18,0 & 22,0 & 3.1 \\
Gordura \% & 2,0 & 11,0 & 4.1 \\
Matéria Mineral \% & 9,0 & 9,0 & - \\
Sólidos totais \% & - & - & 13.18 \\
\hline *Composição de acordo com os níveis de garantia do fabricante. ** valores para composição do leite de acordo com Guerra (2016), \\
experimento que ocorreu no mesmo período.
\end{tabular}

Para o acompanhamento do desempenho dos animais, foram realizadas pesagens a cada sete dias. O ganho de peso total (GPT) foi calculado pela diferença entre o peso final e o peso inicial dos animais. Já o ganho de peso médio diário (GMD) foi obtido pela divisão do GPT pela quantidade de dias de permanência no experimento, expresso em $\mathrm{kg} /$ dia. Após a pesagem aos 30 e 60 dias de idade, foram medidas a altura de cernelha, larguras de garupa e peito e comprimento corporal utilizandose um hipômetro, e o perímetro torácico, com fita métrica, circundando o corpo do animal posteriormente aos membros anteriores e cruzando-se acima da cernelha.

A análise econômica foi realizada pela comparação entre a receita estimada na atividade produtiva e os custos operacionais. Todos os preços utilizados nos cálculos foram os praticados no período de março e abril de 2015, obtidos por consulta à lista de preços pagos pelo produtor na região da Grande Natal-RN. Os preços de estimativa de venda foram estabelecidos com base naqueles praticados na região da Grande Natal, e considerado que a arroba do vitelo é $30 \%$ mais valorizada que a arroba convencional (Almeida Júnior et al., 2008).

Os indicadores econômicos utilizados para compor o custo operacional total (COT) foram: custo total do concentrado $=$ (quantidade consumida de concentrado multiplicada pelo seu preço de aquisição); custo total da dieta líquida $=$ (quantidade consumida de leite integral ou sucedâneo multiplicado pelo seu preço de aquisição); custo com mão de obra = quantidade de horas trabalhadas, multiplicada pelo valor da hora de trabalho, subtotal $=$ (somatório dos custos com dieta, mão de obra e encargos, administração e taxas) e outras despesas diversas foi obtido multiplicando-se o subtotal por 5\% (Reis, 2002). A soma dessas despesas originou o custo operacional total (COT). Equipamentos, animais e a terra, bem como depreciação anual do capital em instalações e equipamentos não entraram nos custos de produção.

As estimativas de receita bruta foram quantificadas pela soma das receitas geradas pelo 
sistema com a venda de carcaças. O custo de oportunidade estimado foi calculado aplicando uma taxa de juros de $6 \%$ ao ano sobre o valor investido no COT (Viana e Silveira, 2008). O lucro operacional estimado (LOPE) foi obtido pela diferença entre a RB e o COT. O Lucro total estimado foi o resultado do LOPE deduzido do custo de oportunidade do capital investido (Reis, 2002). Todos os valores em reais ( $\mathrm{R} \$$ ) foram convertidos para dólar (US\$), levando em consideração a cotação da moeda no período.

Os dados de desempenho e medidas biométricas foram analisados considerando-se o delineamento inteiramente ao acaso, com dois tratamentos e cinco repetições. Os dados foram submetidos à análise variância, levando em consideração o seguinte modelo: $Y \mathrm{ij}=\mu+\mathrm{Di}+\beta \mathrm{ij}$, em que: $\mathrm{Yij}=$ valor observado na dieta $\mathrm{i}$, repetição $\mathrm{j} ; \mu=$ efeito médio geral; $\mathrm{Di}=$ efeito da dieta $\mathrm{i}, \mathrm{i}=$ leite ou sucedâneo; $\beta \mathrm{ij}=$ erro aleatório atribuído à dieta $i$, da repetição $j$.

\section{Resultados e Discussão}

Foi observado efeito da dieta líquida no peso final dos bezerros (Tabela 2), onde aqueles animais que receberam leite integral tiveram maiores valores de peso final. Esse resultado é reflexo do ganho de peso diário, que teve comportamento semelhante ao peso final dos animais. Os ganhos de pesos observados são maiores que os relatados por Boito et al. (2015) para animais alimentados somente com leite, $0,398 \mathrm{~kg} / \mathrm{dia}$ e $0,198 \mathrm{~kg} /$ dia para os animais que receberam apenas sucedâneo. Mesmo com variação numérica nos valores das pesquisas, fica claro que os animais que recebem leite integral em sua dieta líquida na fase de cria têm o desempenho melhorado. Fato este também observado na literatura, cujas pesquisas relatam que o desempenho dos bezerros que recebem sucedâneo é em média de $20 \%$ a $30 \%$ inferior aos animais tratados somente com leite integral (França et al., 2011; Boito et al., 2015).

Tabela 2. Médias para peso inicial, peso final, ganho médio diário (GMD) e ganho de peso total (GPT) de bezerros leiteiros na fase de cria alimentados com diferentes dietas líquidas.

\begin{tabular}{lcccc}
\hline \multirow{2}{*}{ Variáveis } & \multicolumn{2}{c}{ Tratamentos } & \multirow{2}{*}{ EPM } & \multirow{2}{*}{ Valor de P } \\
\cline { 2 - 3 } & Leite integral & Sucedâneo & & 0,892 \\
Peso inicial $(\mathrm{kg})$ & 26,50 & 26,40 & 0,340 & 0,8920 \\
Peso Final $(\mathrm{kg})$ & 56,30 & 45,10 & 2,920 & 0,046 \\
GMD (kg/dia) & 0,500 & 0,310 & 0,040 & 0,026 \\
GPT (kg) & 29,80 & 18,70 & 2,680 & 0,027 \\
\hline
\end{tabular}

EPM: erro padrão da média.

Essas diferenças de ganho de peso para animais que recebem leite integral em relação aos substitutos lácteos disponíveis no mercado são atribuídas a diversos fatores. Boito et al. (2015) atribuíram esse efeito ao valor biológico do sucedâneo, que é menor que o do leite integral e apresenta uma menor taxa de absorção dos nutrientes quando comparados ao leite integral. Além de atributos nutricionais influenciarem no ganho de peso dos animais, outro fator determinante diz respeito às características organolépticas dos substitutos lácteos, o que dificulta a adaptação dos animais a essa dieta (França et al., 2011; Schäff et al., 2018).

Cabe salientar, que mesmo sendo observado uma diferença de $38 \%$ no ganho de peso dos animais que receberam leite em relação ao sucedâneo, a variação é condizente com o desempenho esperado dos animais neste período, uma vez que o ganho preconizado pelo NRC
(2001) situa-se entre 0,200 a $0,400 \mathrm{~kg} /$ bezerro/dia. Essas informações também podem ser relevantes na criação de fêmeas que irão compor o plantel no futuro. Quanto menor o ganho de peso nessa fase, mais tempo a bezerra passará nas fases subsequentes, o que pode onerar ainda mais os custos de produção para animais de reposição.

Não foi observado efeito da dieta líquida para as medidas biométricas aos 30 e 60 dias de idade (Tabela 3). Esses resultados são justificados pelo fato de que na fase inicial de crescimento, bezerros de aptidão leiteira apresentam o pico de exigência de energia líquida de mantença, sendo que essa energia é desviada para crescimento de órgãos internos, principalmente fígado e trato gastrointestinal e para depósitos de gordura interna, os quais possuem intensa atividade metabólica nesta fase (White et al., 2015), sem priorizar o direcionamento de nutrientes para deposição tecido ósseo e muscular. Portanto, supostamente o maior 
ganho de peso observado para os bezerros que receberam leite integral (Tabela 2) foi devido ao maior aporte de nutrientes fornecido pelo leite que foi direcionado para o crescimento de órgãos internos e para depósitos de gordura mesentérica e perirrenal.

Tabela 3. Médias altura de cernelha (AC), comprimento corporal (CC), perímetro torácico (PT) e largura de garupa (LG), largura de peito (LP) de bezerros com aptidão leiteira na fase de cria alimentados com diferentes dietas líquidas.

\begin{tabular}{|c|c|c|c|c|}
\hline \multirow{2}{*}{ Variáveis (cm) } & \multicolumn{2}{|c|}{ Tratamentos } & \multirow[b]{2}{*}{ EPM } & \multirow[b]{2}{*}{ Valor de $\mathbf{P}$} \\
\hline & Leite & Sucedâneo & & \\
\hline \multicolumn{5}{|c|}{------ 30 Dias ------- } \\
\hline $\mathrm{AC}$ & 81,3 & 79,8 & 1,06 & 0,507 \\
\hline $\mathrm{CC}$ & 66,6 & 67,6 & 0,895 & 0,622 \\
\hline PT & 81,7 & 78,5 & 1,64 & 0,368 \\
\hline LG & 21,9 & 21,0 & 0,546 & 0,450 \\
\hline LP & 20,7 & 18,5 & 0,726 & 0,130 \\
\hline \multicolumn{5}{|c|}{------- 60 Dias ------- } \\
\hline $\mathrm{AC}$ & 86,1 & 82,3 & 1,41 & 0,192 \\
\hline $\mathrm{CC}$ & 74,7 & 69,0 & 2,88 & 0,359 \\
\hline PT & 90,3 & 89,1 & 2,27 & 0,810 \\
\hline LG & 24,1 & 22,7 & 0,748 & 0,391 \\
\hline LP & 22,0 & 20,1 & 0,833 & 0,286 \\
\hline
\end{tabular}

EPM: erro padrão da média.

Os resultados observados nesse trabalho para as medidas biométricas foram semelhantes aos observados por Teixeira et al. (2007), os autores avaliaram o efeito de diferentes dietas sobre o desempenho de bezerros da raça holandesa durante o período de aleitamento. Aita et al. (2006) e Oliveira et al. (2015) mostraram em suas pesquisas ausência de efeito da dieta nas medidas biométricas de bezerros na fase de cria, corroborando com os resultados observados nesse trabalho.

O item de maior participação nos custos de produção, independentemente do tipo de dieta usada no aleitamento, foi a dieta (líquida e concentrada), representou $70 \%$ e $75 \%$ para sucedâneo e leite integral, respectivamente (Figura 1). Guerra et al. (2010) afirmam que a nutrição é o item que mais onera os sistemas de produção animal, esse corresponde de $70 \%$ a $80 \%$ dos custos de produção. Do mesmo modo, Reis et al. (2018) relataram que durante os primeiros 90 dias de vida, a alimentação das bezerras foi responsável por $89,2 \%$ do custo operacional total.

Dentro da dieta líquida o leite integral tornou o sistema mais oneroso em relação ao sucedâneo, pois o custo por litro de leite foi de US\$ 0.45 totalizando um gasto de 109.1 US\$/bezerro. Isso se justifica pelo fato de que o sucedâneo representou uma economia de $50 \%$ (US\$ 0.22 por litro do sucedâneo nos anos de 2014/2015) em relação ao preço do litro de leite. Reis et al. (2018) quando avaliaram o custo de produção de fêmeas bovinas leiteiras durante as fases de cria e de recria constataram que durante os primeiros 90 dias de vida, o leite fornecido foi o item com a maior representatividade $(75,6 \%)$, em função da dieta líquida (leite integral) que os animais receberam. $\mathrm{O}$ menor custo do sucedâneo é a principal justificativa de seu uso em relação ao leite integral, haja vista que os animais que recebem sucedâneo têm seu desempenho inferior quando comparados aos que recebem leite (Tabela 2).

Levando em consideração que o consumo de concentrado por bezerros, na fase de aleitamento é baixo, e a dieta líquida (leite ou sucedâneo) é a principal fonte de nutrientes para os bezerros nessa fase. O CTC se comportou de forma contrária a fração líquida (Figura 1), observou-se um maior custo para os bezerros que receberam o substituto lácteo. Essa superioridade supostamente é justificada pelo maior consumo de matéria seca proveniente do concentrado inicial dos animais que receberam sucedâneo, causado principalmente pela menor qualidade desse sucedâneo em comparação ao leite, promovendo um maior consumo de concentrado para suprir as exigências nutricionais (Nascimento et al., 2009; Boito et al., 2015).

Os substitutos do leite são formulados com finalidade de estimular uma maior ingestão de concentrado (Bartlett et al., 2005). França et al. (2011) observaram maior ingestão de concentrado em animais que receberam sucedâneo em relação aos animais que receberam leite em sua dieta. 
Dessa forma, os maiores custos da fração sólida da dieta justificaram-se pelo maior consumo da mesma pelos animais alimentados com sucedâneo.

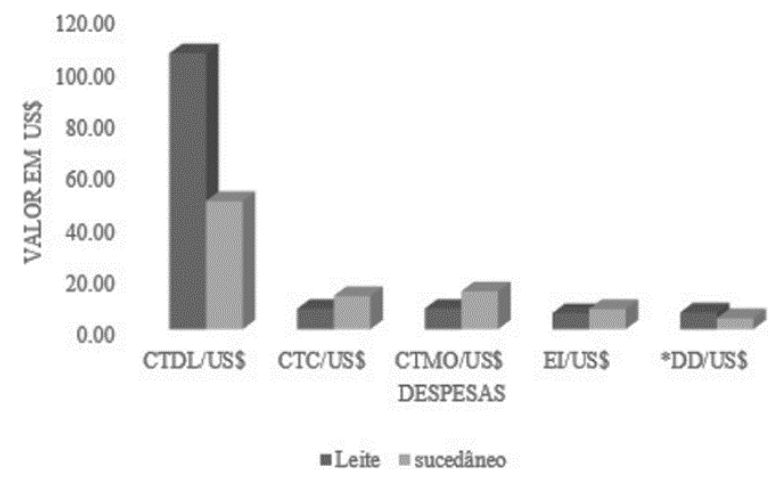

Figura 1. Custo operacional de produção por bezerros com aptidão leiteira na fase de cria alimentados com dois métodos de aleitamento. Custo total da dieta líquida (CTDL), custo total do concentrado (CTC), custo total com mão de obra (CTMO), encargos e impostos (EI), e despesas diversas (DD).

O custo com a mão de obra foi o segundo item mais representativo dentro dos custos de produção independente da dieta adotada. Santos e Lopes (2014) avaliaram custos de produção de fêmeas bovinas leiteiras, também verificaram que a mão de obra é o segundo item que mais onera os custos de produção, ficando atrás apenas da alimentação. Uma maneira de otimizar a mão de obra é aumentar a quantidade de animais com o mesmo número de funcionários, desde que as condições básicas de trabalho sejam mantidas (Resende et al., 2016).

Entre as dietas utilizadas, o sucedâneo teve maior custo com mão de obra ( $16,0 \%$ vs $6,0 \%)$, isso pelo fato que foi desprendido uma hora a mais de serviço, devido a preparação do produto antes do fornecimento para os bezerros. Os demais itens (DD, EI) corresponderam, respectivamente, a 5,0\% e $4,0 \%$, do custo de produção para o leite e $9,0 \%$ e $5,0 \%$, respectivamente, para o sucedâneo.

A receita bruta estimada com a venda de carcaças foi maior para os animais que receberam dieta líquida a base de leite integral (Tabela 4), os animais que receberam essa dieta tiveram um maior ganho médio diário e total, o que refletiu em maior peso final dos animais (Tabela 2), isso possibilita um maior rendimento em caso de abate logo após a fase de cria.

O custo operacional total (Tabela 4) foi maior para os animais que receberam o leite integral como dieta líquida, a principal justificativa para esse fato é o preço do litro de leite, tendo um valor $50 \%$ superior em relação ao sucedâneo. O que torna o substituto lácteo uma ferramenta importante para reduzir custos. O custo de oportunidade estimado teve comportamento semelhante ao custo operacional total, visto que foi utilizada a mesma taxa de remuneração do capital investido (6\% ao ano).

Tabela 4. Receitas e indicadores econômicos estimados na produção de bezerros com aptidão leiteira na fase de cria alimentados com dois métodos de aleitamento.

\begin{tabular}{llc}
\hline Variáveis (US\$) & Leite & Sucedâneo \\
\hline Receita bruta estimada & 549,5 & 353,1 \\
Custo operacional total & 689,7 & 454,4 \\
Custo de oportunidade estimado & 731,1 & 481,6 \\
Lucro operacional estimado & $-140,1$ & $-101,2$ \\
Lucro total estimado & $-871,2$ & $-582,9$ \\
\hline
\end{tabular}

O balanço econômico negativo para ambas as dietas líquidas utilizadas, evidencia que ambas são inviáveis, pois fica abaixo do percentual utilizado para taxa de remuneração do capital investido. Porém, esses gastos podem ser diluídos nas fases subsequentes. Para sistemas de produção de bezerras, onde a criação é praticamente obrigatória, a viabilidade econômica dependerá da finalidade do sistema de produção e do manejo nutricional nas fases posteriores à de aleitamento. Guerra et al. (2010) demonstraram que a venda de novilhas de aproximadamente 14 meses possibilitou uma margem bruta de $27,0 \%$, o que torna criação de novilhas uma alternativa para diversificar a receita das propriedades leiteiras.

\section{Conclusão}

Bezerros com aptidão leiteira que utilizam leite bovino integral como fonte de nutrientes na fase de cria na dieta líquida, apresentam um desempenho superior aos que recebem sucedâneo. Mesmo com desempenho superior, o leite integral tornou o sistema mais oneroso. O sucedâneo mostrou-se uma alternativa para diminuir custos. 


\section{Conflito de Interesse}

Os autores declaram não existir conflito de interesse.

\section{Comitê de ética}

O trabalho foi aprovado pelo Comitê de Ética no uso de animais da UFRN sob protocolo $n^{\circ}$ 026/2015.

\section{Agradecimentos}

Os autores agradecem ao programa de educação tutorial (PET) do curso de Zootecnia da Universidade Federal do Rio Grande do Norte (UFRN), a empresa SOCIL e aos funcionários do setor de bovinocultura de leite da escola agrícola de Jundiaí (EAJ - UFRN) pelo apoio na execução dessa pesquisa.

\section{Referências}

Aguilar, G.C.; Lopes, M.A.; Cardoso, M.G. Diagnóstico de propriedades leiteiras em regime de agricultura familiar no município de Ponto dos Volantes (MG). Medicina Veterinária (UFRPE), 12(4): 290-294, 2018.

Aita, M.F.; Fischer, V.; Stumpf Jr., W. Efeitos dos níveis de extrato etéreo no sucedâneo do leite sobre o desenvolvimento corporal de bezerros Jersey. Revista Brasileira de Zootecnia, 35(1): 193-202, 2006.

Almeida Júnior, G.A.; Costa, C.; Carvalho, S.M.R.; Persichetti Júnior, P.; Panichi, A. Desempenho de bezerros holandeses alimentados após o desaleitamento com silagem de grãos úmidos ou grãos secos de milho ou sorgo. Revista Brasileira de Zootecnia, 37(1), 148-156, 2008.

Bartlett, K.S.; McKeith, F.K.; VandeHaar, M.J.; Dahl, G.E.; Drackley, J.K. Growth and body composition of dairy calves fed milk replacers containing different amounts of protein at two feeding rates. Jornal of Animal Science, 84(6): 1454-467, 2005.

Boito, B.; Menezes, L.F.G.; Ziech, M.F.; Kuss, F.; Lisbinski, E.; Fiorelli, A. Uso de sucedâneo em substituição ao leite no desempenho de bezerros da raça holandesa durante a cria e recria. Ciência Animal Brasileira, 16(4):498-507, 2015.

Conceição, T.G.R.; Lopes, M.A.; Cardoso, M.G.C.; Vieira, J.A.; Pereira, A.B. Diagnóstico da cria e recria de bezerras em propriedades leiteiras no município de Corinto
(MG). Medicina Veterinária (UFRPE), 12(4): 212-221, 2018.

França, S.R.A.; Coelho, S.G.; Carvalho, A.U.; Martins, R.G.R.; Ribeiro, S.L.M. Desempenho de bezerros alimentados usando de sucedâneo até 56 dias de idade. Revista Ceres, 58, (6), 790-793, 2011.

Guerra, M.G. Milho e ureia em substituição ao farelo de soja para vacas em lactação a pasto. 2016. 110 p. Tese (Doutorado) Universidade Federal Rural de Pernambuco, Recife-PE, 2016.

Guerra, M.G.; Guilhermino, M.M.; Rangel, A.H.N.; Medeiros, H.R.; Lima Junior, D.M. Custo operacional total na cria e recria de bovinos leiteiros. Revista Verde de Agroecologia e Desenvolvimento Sustentável, 5(3): 172-178, 2010.

Nascimento, P.V.N.; Silva, F.F.; Veloso, C.M.; Bonomo, P.; Teixeira, F.A.; Gonsalves Neto, J. Exigências nutricionais de bezerros da raça Holandesa alimentados com concentrado e feno de capim-elefante. Revista Brasileira de Zootecnia, 38(8): 1605-1613, 2009.

NRC - National Research Council. Nutrients Requirements of Dairy Cattle. National Academies Press, Washington, 381p, 2001.

Oliveira, M.V.M.; Abreu, C.; Vargas Júnior, F.M.; Fernandes, H.J.; Salla, L.E. Efeito do feno de leguminosas no desempenho de bezerros lactentes. Revista Ciência Agronômica, 46(3): 654-660, 2015.

Reis, R.P. Fundamentos de economia aplicada. Lavras: UFLA/FAEPE, 2007. 95p.

Reis, E.M.B.; Lopes, M.A.; Santos, G.; Guimarães, A.M. Custo de produção de fêmeas bovinas leiteiras durante as fases de cria e de recria: um estudo de caso. Medicina Veterinária (UFRPE), 12(1): 37-45, 2018.

Resano, H.; Olaizola, A. M.; Dominguez-Torreiro M. Exploring the influence of consumer characteristics on veal credence and experience guarantee purchasing motivators.

Meat Science, 141(7): 1-8, 2018.

Resende, J.C.; Freitas, A.F.; Pereira, R.A.N.; Silva, H.C.M.; Pereira, M.N. Determinantes de lucratividade em fazendas leiteiras de Minas Gerais. Arquivo Brasileiro de Medicina Veterinária e Zootecnia, 68(4): 1053-1061, 2016.

Salles, M.S.V.; Lucci, C.S. Monensina para Bezerros Ruminantes em Crescimento Acelerado. 1. Desempenho. Revista 
Brasileira de Zootecnia, 29(2): 573-581, 2000.

Santos, G.; Lopes, M.A. Custos de produção de fêmeas bovinas leiteiras do nascimento ao primeiro parto. Ciência Animal Brasileira, 15(1): 11-19, 2014.

Schäff, C.T.; Gruse, J.; Maciej, J.; Pfuhl, R.; Zitnan, R.; Rajsky, M.; Hammon, H.M. Effects of feeding unlimited amounts of milk replacer for the first 5 weeks of age on rumen and small intestinal growth and development in dairy calves. Journal of Dairy Science, 101(1): 783-793, 2018.

Teixeira Júnior, F.E.P.; Lopes, M.A.; Ruas, J.R.M.; Costa, M.D.; Rocha Júnior, V.R. Efeito da frequência de ordenhas de vacas mestiças na rentabilidade da atividade leiteira. Medicina Veterinária (UFRPE), 11(1): 53-61, 2017.

Teixeira, P.A.; Oliveira, M.D.S.; Sousa, C.C.; Silva, T.M. Avaliação de diferentes dietas sobre o desempenho de bezerros da raça holandesa durante o período de aleitamento. Ciência e Agrotecnologia, 31(6): 1831-1837, 2007.

Thorthwaite, C.W. An approach toward a rational classification of climate. Geographic Review, 38(1): 55-93, 1948.

Viana, J.G.A.; Silveira, V.C.P. Custos de produção e indicadores de desempenho: Metodologia aplicada a sistemas de produção de ovinos. Custos e @gronegócio on line, 4(3): 2-27, 2008.

White, D.S.; Duberstein, K.J.; J.L.F.; Bohlen, Bertrand, J.K.; Nelson, A.H.; Froetschel, M.A.; Davidson, B.E.; Graves, W.M. Allometric comparison of Georgia dairy heifers on farms and at youth shows. Journal of Dairy Science, 98(2): 1345-1353, 2015. 